\title{
Increasing prevalence of atopic eczema in Taiwanese adolescents from 1995 to 2001
}

\author{
Y.-L. Lee* ${ }^{*}$, C.-W. Li ${ }^{\dagger}$, F.-C. Sung ${ }^{\ddagger}$, and Y.L. Guo ${ }^{\S}$ \\ * Department of Occupational and Environmental Medicine, National Cheng Kung University, Tainan, Taiwan, ${ }^{\dagger}$ Department of Internal Medicine, National Cheng \\ Kung University Hospital, Tainan, Taiwan, ${ }^{\ddagger}$ Institute of Environmental Health, China Medical University, Taichung, Taiwan and ${ }^{\S}$ Department of Environmental and \\ Occupational Medicine, National Taiwan University (NTU) and NTU Hospital, Taipei, Taiwan
}

\section{Clinical and Experimental Allergy}

Correspondence:

Y. L. Guo, Department of Environmental and Occupational Medicine, National Taiwan University (NTU) and NTU Hospital, 1 Sec 1, Jen-Ai Road, Taipei 100, Taiwan. E-mail: leonguo@ha.mc.ntu.edu.tw

\begin{abstract}
Summary
Background The prevalence of atopic eczema in adolescents has recently been reported as increasing in many countries, a phenomenon yet to be fully explained. This study compared the prevalence of atopic eczema among Taiwanese adolescents with individual-level risk factors and community-level data of temperature, relative humidity, and air pollutants to determine whether changes in these factors could explain the observed change in prevalence. Methods We conducted two nationwide, cross-sectional surveys of atopic illness and symptoms among Taiwanese 12-15-year-old schoolchildren in 1995-1996 and 2001. The effects of personal and environmental factors were assessed and temporal changes of outdoor monitoring data were also compared with the prevalence difference of atopic eczema.

Results A total of 42919 adolescents from the 1995 to 1996 survey and 10215 adolescents from the 2001 survey attended schools located within $1 \mathrm{~km}$ of 22 monitoring stations. The 12 -month prevalence of atopic eczema increased significantly during this period [adjusted prevalence ratio $(\mathrm{PR})=1.43,95 \%$ confidence interval $(\mathrm{CI}) 1.21-1.70$ in boys; $\mathrm{PR}=1.77,95 \% \mathrm{CI}$ 1.49-2.10 in girls]. After adjustment for potential risk factors, the prevalence differences were statistically unchanged. Although parental education level contributed the most, changes in personal and environmental factors might not explain the observed prevalence increases of atopic eczema. Temporal change in the relative humidity was significantly associated with prevalence increase among boys but its contribution was also small.

Conclusion Correlates of the investigated risk factors that have changed over time still underlie the prevalence increases of atopic eczema in Taiwanese adolescents. The exact reasons for the rising trends remain to be elucidated.
\end{abstract}

Keywords adolescents, atopic eczema, prevalence, risk factor, Taiwan

Submitted 5 September 2006; revised 16 December 2006; accepted 7 February 2007

\section{Introduction}

Atopic eczema, a chronic, relapsing skin disease characterized by pruritus and a propensity to affect the flexural areas, is now the most common inflammatory skin disease in children $[1,2]$. There is evidence suggesting that the prevalence of this evolving epidemic has increased substantially over recent years [3-8]. The changing pattern has not been fully explained, in part because of an incomplete understanding of its pathogenesis. Some researchers, however, have indicated that the increase has slowed or ceased [9-11], and some have even reported the prevalence as decreasing $[12,13]$.
Both genetic and environmental factors are believed to be associated with the prevalence of atopic eczema [14]. Because the changes in prevalence have been too rapid to be accounted for by changes in gene frequencies, environmental factors have been suggested as possible contributors [15-19]. There are also possibly changes over time in the proportions of these factors between people with atopic eczema. A consensus that this evolving epidemic is indeed increasing has prompted discussion regarding what kinds of factors might be responsible. However, to date, population studies exploring the effects of these variables are limited. 
Recently, in Taiwan, secular trends in the prevalence of atopic eczema have been examined in only one study. By using recurrent itchy rash in a typical distribution as the indicator, Yan et al. [3, 20] reported that the 12-month prevalence of atopic eczema had increased from 1.4\% in 1994 to $4.1 \%$ in 2001 among 13-14-year-old adolescents. However, this was a local study, restricted to schoolchildren in Taipei City, and the possible contributing factors were not clearly documented. To the best of our knowledge, there is no other study that compares trends of atopic eczema throughout Taiwan.

Compared with data all over the world, the 12-month prevalence of atopic eczema in Taiwan was around the lower range of the reported values [1,3]. The data for this study come from the standardized 'International Study of Asthma and Allergies in Childhood'-Chinese version (ISAAC-C) questionnaire used in two national surveys in 1995-1996 and 2001. The first aim of the study was to determine the actual time trend of atopic eczema in adolescents in a country with a low prevalence, and compare the sex difference. The second was to investigate whether changes in selected individual-level risk factors between two surveys could explain any observed change in prevalence. The third was to compare changes in air pollution and meteorology data with changes in the prevalence of atopic eczema in order to assess their relationship.

\section{Materials and methods}

\section{Study design}

Between November 1995 and May 1996, a nationwide mass screening ISAAC survey was conducted for asthma, rhinitis, and eczema among middle-school students. A total of 800 middle schools and more than one million students were investigated. The study protocol has been described previously [21, 22], and was replicated in the 2001 survey. Briefly, the identical standardized ISAAC-C questionnaire was taken home by students and answered by parents. Classroom incentives but not individual incentives were used to encourage participation.

In order to compare outdoor air pollution and meteorology data with questionnaire results, we investigated schools within $1 \mathrm{~km}$ catchment areas of Taiwan Environmental Protection Agency (EPA) air monitoring stations (Fig. 1). Between February and June 2001, a total of 22 middle schools in Taiwan's 22 counties were randomly chosen for the second survey. Student sampling was stratified by grade in each school. Participants in both surveys were all aged between 12 and 15. Data from the 2001 survey and data from the identical 22 middle schools in the 1995-1996 survey were combined for further analysis.

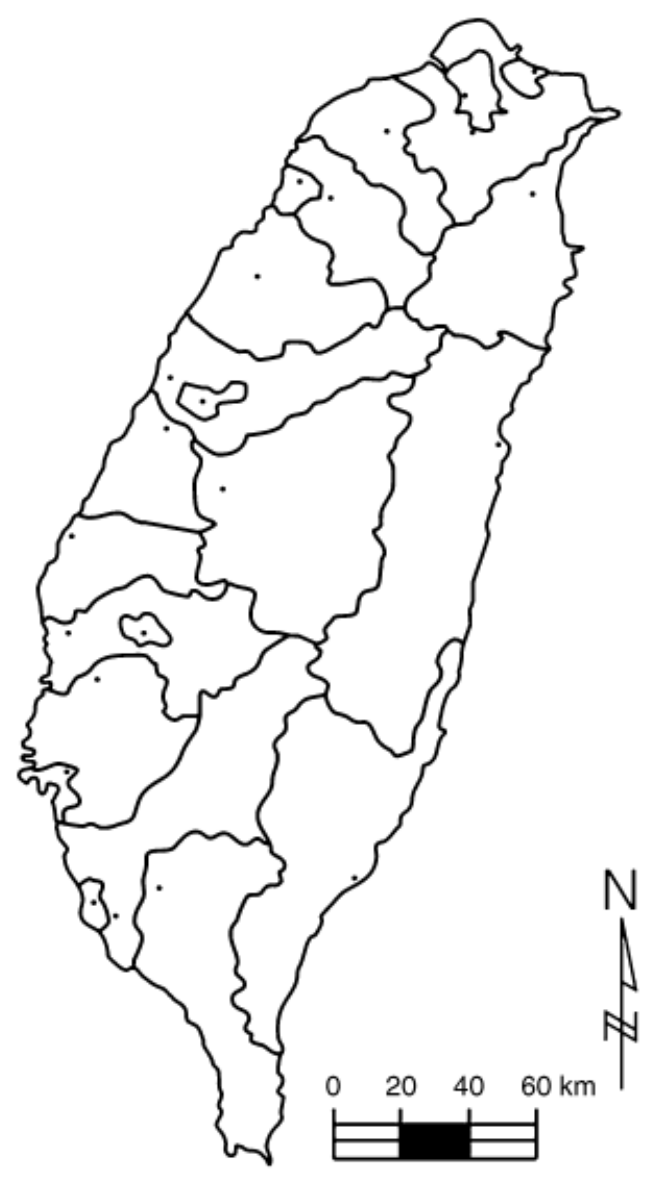

Fig. 1. Twenty-two Taiwan Environmental Protection Agency monitoring stations in this study. Circles indicate $1 \mathrm{~km}$ catchment areas.

\section{Definition of atopic eczema and covariates}

Whether or not a child was deemed to suffer from atopic eczema was determined by positive responses to the questions, 'Have your child ever had an itchy rash which was coming and going for at least six months?' and 'Has your child had this itchy rash at any time in the past 12 months?' If both the answers were 'yes', the parent would be further asked, 'Has this itchy rash at any time affected any of the following places: the folds of the elbows, behind the knees, in front of the ankles, under the buttocks, or around the neck, ears, or eyes?' In our study, children who were reported to suffer from a skin rash in the previous year occurring at specific locations were defined as having atopic eczema.

Many individual-level predictors have been identified for childhood allergic diseases. We also collected data on current status of demographic and environmental factors, including sex, age, parental education level, active smoking habits, passive smoke exposure at home, exercise habits, and incense burning at home. Some personal data, such as active smoking habits, were reported by students themselves in both surveys. All responses compared in this report were to identical questions in the two surveys. 
The study protocol was approved by the Institutional Review Board at our university hospital and it complied with the principles outlined in the Helsinki Declaration [23].

\section{Air pollution and meteorology data}

Complete monitoring data for the air pollutants sulphur dioxide $\left(\mathrm{SO}_{2}\right)$, carbon monoxide (CO), ozone $\left(\mathrm{O}_{3}\right)$, nitrogen oxides $\left(\mathrm{NO}_{x}\right)$, and particles with an aerodynamic diameter of $10 \mu \mathrm{m}$ or less $\left(\mathrm{PM}_{10}\right)$, as well as daily temperature and relative humidity were available from EPA monitoring stations from 1995. Concentrations of each pollutant were measured continuously and reported hourly $-\mathrm{SO}_{2}$ by ultraviolet fluorescence, CO by non-dispersive infrared absorption, $\mathrm{O}_{3}$ by ultraviolet absorption, $\mathrm{NO}_{x}$ by chemiluminescence, and $\mathrm{PM}_{10}$ by $\beta$-gauge. All sampling and analysing methods were identical throughout our study period. Hourly and daily data were combined to calculate the monthly average. We used regression model to assess the slopes of the monthly average of temperature, relative humidity, and air pollutants from 1995 to 2000, and estimated the change of each between the study period of two surveys in every community.

\section{Statistical analysis}

All analyses were stratified by sex. Missing or inconsistent responses were included in the denominator for prevalence calculations, but excluded from subsequent bivariate analysis according to ISAAC recommendations [11]. Prevalence rates were directly standardized for age based on distribution in the 1995-1996 survey. Bivariate analyses were conducted to determine the relative effectiveness of each potential risk factor on atopic eczema. In order to investigate whether changes in the distributions of these factors between two surveys could explain the observed change in prevalence, the prevalence differences (2001 survey-1995-1996 survey) for atopic eczema were shown and attributable risks were calculated by comparing prevalence differences before and after adjustment for each risk factor.

Previously reported analyses of ecological outcomes have demonstrated a larger inter-city variation than would be predicted by inter-individual variation [21, 22, 24]. We used two-stage methods to derive more precise estimates of site-specific parameters and site-level effects, and correct for any excess between-site variability and adjust for multiple comparisons. In the first step, a logistic regression model was used to estimate the adjusted prevalence rates of atopic eczema among schoolchildren in each community, controlling for the individual-level covariates. The goodness of fit was also accessed with likelihood ratio tests to determine whether a variable contributed significantly to the model. Then, we calculated the adjusted prevalence change for each school. In the second step, these community-specific prevalence changes of atopic eczema were regressed against the estimated changes in temperature, relative humidity, and air pollutants between two surveys, using weights proportional to the inverse variance $\left(1 /\right.$ standard error $\left.^{2}\right)$ of the adjusted prevalence rates.

\section{Results}

Between February and June 2001, a total of 11738 students and their parents from 22 middle schools were investigated. Data from 10215 subjects was deemed satisfactory, with an overall response rate of $87.0 \%$. There were 42919 responses (response rate 86.9\%) selected from the identical schools in the 1995-1996 survey. In both surveys, the response rates were independent and mutually exclusive of the reported diseases or symptoms. Compared with the 1995-1996 survey, children in the 2001 survey seem to be slightly older (13.6 years vs. 13.3 years) and to have a higher proportion of females (51.3\% vs. $49.7 \%$ ). Table 1 shows the changes in age-standardized prevalence rates of atopic eczema during two surveys.

Prevalence rates in boys increased from $2.65 \%$ in 1995-1996 to 4.15\% in 2001 [adjusted prevalence ratio (PR) 1.51, 95\% confidence interval (CI) 1.28-1.78]. Prevalence rates in girls also increased from $2.22 \%$ in 1995-1996 to 3.91\% in 2001. After adjustment for all covariates that might lead to differential responses, PRs in both sexes decreased but were statistically unchanged (Table 1). The increases over the 6-year period were more marked among girls than boys. The adjusted PR of atopic eczema in boys compared with girls in the 1995-1996 survey was 1.19 (95\% CI 1.06-1.35), while it was 1.08 (95\% CI 0.89-1.31) in the 2001 survey (data not shown).

In Table 2, the basic tabulation of unweighted prevalence by risk factors is presented for each survey. Younger subjects, higher parental education levels, active smoking

Table 1. Comparison of age-standardized prevalence (\%) of atopic eczema among Taiwanese adolescents in 1995-1996 and 2001 surveys

\begin{tabular}{lllll}
\hline & & $\begin{array}{l}\text { PR adjusted for age } \\
\text { and month of } \\
\text { investigation } \\
(95 \% \text { CI })\end{array}$ & $\begin{array}{l}\text { PR adjusted for } \\
\text { all covariates* } \\
(95 \% \text { CI })\end{array}$ \\
\hline Boys & 2.65 & 4.15 & $1.51(1.28-1.78)$ & $1.43(1.21-1.70)$ \\
Girls & 2.22 & 3.91 & $1.83(1.55-2.15)$ & $1.77(1.49-2.10)$ \\
All $^{\dagger}$ & 2.44 & 4.03 & $1.66(1.48-1.87)$ & $1.61(1.42-1.81)$ \\
\hline
\end{tabular}

PR indicates prevalence ratio and CI indicates confidence interval. All tests in the table are with $P<0.001$.

*Age, month of investigation, community, parental education, smoking habit, exercise habit, cigarette consumption at home, and incense burning at home.

${ }^{\dagger}$ Besides other covariates, adjusted also for sex. 


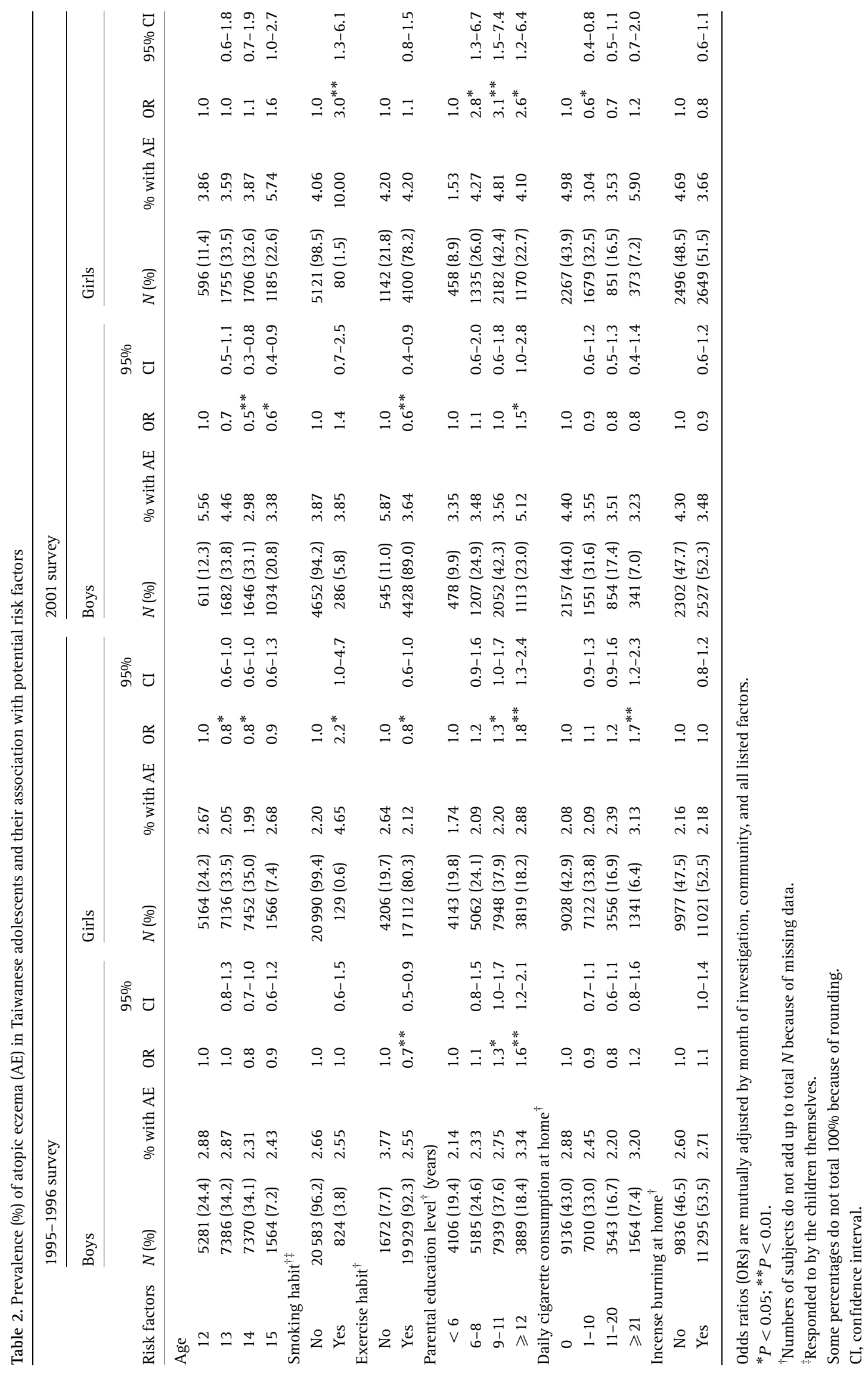


Table 3. Prevalence difference (PD) and attributable risk (AR) for atopic eczema between 1995-1996 and 2001 surveys in Taiwanese adolescents, adjusted for potential risk factors

\begin{tabular}{|c|c|c|c|c|c|c|c|c|c|c|}
\hline & \multirow{2}{*}{$\begin{array}{l}\text { Levels of } \\
\text { factors }\end{array}$} & \multicolumn{3}{|l|}{ Boys } & \multicolumn{3}{|l|}{ Girls } & \multicolumn{3}{|l|}{ All } \\
\hline & & $\mathrm{PD}^{*}(\%)$ & $95 \% \mathrm{CI}$ & AR $(\%)$ & $\mathrm{PD}^{*}(\%)$ & $95 \% \mathrm{CI}$ & AR $(\%)$ & $\mathrm{PD}^{\dagger}(\%)$ & $95 \% \mathrm{CI}$ & $\mathrm{AR}(\%)$ \\
\hline Age + month of investigation + community & & 1.68 & $1.00-2.46$ & & 2.20 & $1.52-2.99$ & & 1.96 & $1.47-2.51$ & \\
\hline Smoking habit ${ }^{\ddagger}$ & 2 & 1.64 & $0.96-2.41$ & 2.2 & 2.15 & $1.47-2.94$ & 2.3 & 1.91 & $1.44-2.48$ & 2.2 \\
\hline Exercise habit & 2 & 1.60 & $0.93-2.37$ & 4.6 & 2.18 & $1.50-2.97$ & 0.8 & 1.92 & $1.43-2.47$ & 1.9 \\
\hline Parental education & 4 & 1.58 & $0.90-2.37$ & 5.8 & 2.10 & $1.42-2.90$ & 4.5 & 1.86 & $1.36-2.41$ & 5.1 \\
\hline Cigarette consumption at home & 4 & 1.67 & $0.99-2.46$ & 0.3 & 2.22 & $1.53-3.02$ & -0.8 & 1.96 & $1.47-2.52$ & -0.1 \\
\hline Incense burning at home & 2 & 1.65 & $0.97-2.44$ & 1.5 & 2.29 & $1.58-3.11$ & -4.0 & 1.98 & $1.48-2.54$ & -1.2 \\
\hline All of above & & 1.43 & $0.75-2.20$ & 14.2 & 2.10 & $1.40-2.92$ & 4.7 & 1.80 & $1.30-2.36$ & 8.1 \\
\hline
\end{tabular}

All tests in the table are with $P<0.001$.

All attributable risks are calculated by comparing with the prevalence differences in the first row.

*Calculated after adjustment for age, month of investigation, community, and the index risk factor.

${ }^{\dagger}$ Calculated after adjustment for sex, age, month of investigation, community, and the index risk factor.

${ }^{\ddagger}$ Responded to by the children themselves.

CI, confidence interval.

Table 4. Relationship between prevalence difference (\%) of atopic eczema and temporal changes of temperature, relative humidity, and air pollutants in 22 communities in Taiwan

\begin{tabular}{|c|c|c|c|c|c|c|}
\hline & \multicolumn{2}{|l|}{ Boys } & \multicolumn{2}{|l|}{ Girls } & \multicolumn{2}{|l|}{ All } \\
\hline & Estimate $^{\dagger}$ & $95 \% \mathrm{CI}$ & Estimate $^{\dagger}$ & $95 \% \mathrm{CI}$ & Estimate $^{\ddagger}$ & $95 \% \mathrm{CI}$ \\
\hline Temperature $\left({ }^{\circ} \mathrm{C}\right)$ & 0.13 & -2.66 to 2.92 & 0.39 & -1.61 to 2.39 & 0.22 & -1.91 to 2.34 \\
\hline Relative humidity (\%) & $0.28 * *$ & 0.00 to 0.57 & 0.09 & -0.13 to 0.32 & $0.19^{*}$ & -0.04 to 0.42 \\
\hline $\mathrm{SO}_{2}(\mathrm{ppb})$ & -0.26 & -1.19 to 0.67 & 0.48 & -0.16 to 1.11 & 0.09 & -0.62 to 0.81 \\
\hline $\mathrm{CO}(\mathrm{ppb})$ & -0.04 & -0.22 to 0.14 & -0.02 & -0.15 to 0.11 & -0.03 & -0.16 to 0.11 \\
\hline $\mathrm{O}_{3}(\mathrm{ppb})$ & -0.25 & -0.96 to 0.47 & -0.17 & -0.68 to 0.35 & -0.19 & -0.74 to 0.35 \\
\hline $\mathrm{PM}_{10}\left(\mu \mathrm{g} / \mathrm{m}^{3}\right)$ & 0.10 & -0.10 to 0.30 & 0.01 & -0.14 to 0.15 & 0.06 & -0.09 to 0.21 \\
\hline NO $x(\mathrm{ppb})$ & -0.26 & -0.77 to 0.26 & -0.05 & -0.42 to 0.33 & -0.16 & -0.55 to 0.24 \\
\hline
\end{tabular}

†Prevalence difference is adjusted for age, month of investigation, parental education, smoking habit, and exercise habit.

${ }^{\ddagger}$ Prevalence difference is adjusted for sex, age, month of investigation, parental education, smoking habit, and exercise habit.

${ }^{*} P<0.1 ;{ }^{* *} P<0.05$.

CI, confidence interval.

habits, and no exercise habits were found to be associated with the occurrence of atopic eczema in adolescents. In the development of atopic eczema, girls seemed to be more vulnerable to active smoking habits than boys, and boys could benefit more from exercise habits than girls. We detected no significant differences in associations between two surveys. There were also no significant survey and risk factor interactions (data not shown).

After adjustment for age, month of investigation, and community, the prevalence differences of atopic eczema between the two surveys were $1.68 \%$ (95\% CI 1.00-2.46\%) for boys and 2.20\% (1.52-2.99\%) for girls (Table 3). Changes for most of the risk factors examined were small, the largest being parental education level. After adjustment for all potential risk factors, the prevalence differences were statistically unchanged at $1.43 \%(0.75-2.20 \%)$ for boys and 2.10\% (1.40-2.92\%) for girls. Thus, after allowing for the change in the prevalence rates of atopic eczema that may be attributed to changes in any of these factors, there were unexplained increases of approximately $1.43 \%$ for boys and $2.10 \%$ for girls.

In Table 3, we could find that changes in smoking habit, exercise habit, and parental education level were associated with slight increases in prevalence differences in both sexes. Among these risk factors, the largest was parental education level, which seemed to explain 5.8\% of the increasing prevalence in atopic eczema for boys and $4.5 \%$ for girls. Taken together, changes in the distributions of all the risk factors concerned could explain 14.2\% of the increase for boys and 4.7\% for girls. However, the prevalence differences remained statistically unchanged and we could not attribute the increasing prevalence of atopic eczema to any investigated risk factor.

After controlling for possible individual-level confounders, we regressed the adjusted prevalence differences against the estimated changes in temperature, relative humidity, and air pollutants (Table 4). No correlation was found between air pollutants with the prevalence changes 
of atopic eczema. However, communities with a higher increase in relative humidity were statistically related to a higher prevalence increase in atopic eczema among boys, but not among girls. In average of the 22 communities, the relative humidity was estimated to increase only $0.09 \%$ from 1995 to 2000 (data not shown), which indicated a $0.03 \%$ prevalence increase in atopic eczema among boys, but only $0.01 \%$ among girls.

\section{Discussion}

The present study allows comparison of the prevalence of atopic eczema by two cross-sectional studies, 6 years apart, in independent populations of children attending identical middle schools. Our most important finding was that the 12-month prevalence of atopic eczema in Taiwanese adolescents has significantly increased during recent years, more marked for girls than for boys. The increase was largely unexplained by changing distributions of risk factors including parental education level, active smoking habits, daily cigarette consumption at home, exercise habits, or incense burning at home. We also found that communities with higher relative humidity increases were associated with the prevalence changes of atopic eczema among boys, but not among girls.

Separate studies using different methodologies have rendered the comparison of prevalence difficult. In order to minimize technical bias, we analysed data from the same schools and used standardized procedures for data collection. The ISAAC questions for symptoms of atopic eczema used in the present study have been validated in different parts of the world. Researchers have well predicted atopic eczema diagnosed by dermatologists in United Kingdom [25], Germany [26], and Ethiopia [27]. As identical questionnaires were applied to schoolchildren of similar age, it is most unlikely that the differences in our findings are attributable to any changes of methodology [28]. A valid estimate of the time trend was also allowed.

The assessment of atopic eczema in epidemiological surveys by means of questionnaires is particularly challenging. Asking parents about a medical diagnosis such as eczema may yield unreliable results because 'eczema' is a rather unspecific label for different skin disorders, e.g. contact dermatitis. In addition, the use of medical terms by lay people may change over time. We only used typical symptoms of atopic eczema during the past 12 months as the main outcome measurement, although medical diagnosis of 'eczema' was also included in the ISAAC questionnaire. Our observed increase in prevalence, like the previous ISAAC study by another group in Taiwan [20], may reflect real increases in atopic eczema.

In our data, medical diagnosis of eczema also increased from 7.0\% in 1995-1996 to 8.6\% in 2001. In children with a medical diagnosis of eczema, 17.6\% in 1995-1996 and
$24.9 \%$ in 2001 were reported as having typical symptoms in the past 12 months, whereas in those without such a diagnosis, only $1.3 \%$ and $2.1 \%$ reported such symptoms. Of 1037 children with typical symptoms of atopic eczema in 1995-1996, a diagnosis of eczema was known in 529 instances (51.0\%). In contrast, a diagnosis of eczema was known in 52.7\% of children with typical symptoms in 2001. This does not necessarily mean that the increase is attributable to the increase in parental recognition and awareness of symptoms. The adjusted PR of undiagnosed typical symptoms in the past 12 months was 1.60 (95\% CI 1.33-1.92) between the two surveys. Although the trends may be due in part to changes in the reporting and consulting behaviour of parents and in the labelling of the disease by general practitioners, it does mean that some of these increases are real. As the prevalence of undiagnosed typical symptoms still increased, the increase in the prevalence of atopic eczema could not be attributed solely to a change in diagnostic terminology or recognition by the general population [29].

Sex difference in time trend was another important finding in our study. Although differential parental reporting of symptoms for boys and girls cannot be excluded, in this report, girls had a higher increase in the prevalence of atopic eczema than boys (Table 1). Maziak et al. [11] performed two secular ISAAC surveys among 13-14-year-old schoolchildren in Germany and also found that girls had a higher increase of atopic eczema than boys. Similar sex-related trends on the occurrence of atopic eczema were also reported among 7-13-year-old schoolchildren in Norway [8]. In Switzerland, divergent gender-related trends for atopic eczema were also observed [4]. Speculating on the reasons behind the observed female-led tendency is not easy. The natural history of atopic eczema points towards male predominance in childhood and female predominance from adolescence [30]. Considering this natural history, our results showed that the observed sex-related trends would alleviate the sex difference in prevalence during childhood, and would probably augment it towards more female dominance in future years.

The prevalence of atopic eczema is commonly thought to decrease with increasing age [31]. In this report, boys had a higher prevalence of atopic eczema, which was consistant with a previous study in Singapore [32]. We also found that parental education level was associated with atopic eczema (Table 2). Parents with a higher education level were more anxious about their children's health conditions; therefore, these children would be more likely to be recognized with atopic eczema [33, 34]. Exposure to cigarette smoke in early life may increase a child's susceptibility to the development of atopic diseases and to a more severe expression of atopy in childhood [35]. Active and passive smoke during adolescence would have significant effects on occurrence of atopic eczema 
[15]. From an ecological study conducted in European countries, a positive relationship was found between parental tobacco smoking and atopic eczema among 13-14-year-old adolescents after other variables were controlled [16]. Our findings suggest only a positive relationship between active smoking habits and atopic eczema, mostly marked among girls. Passive exposure to cigarette smoke and incense at home were found to have negative or relatively weak effects. These reflected smoking cessation or avoidance effects, as in other crosssectional studies [22,36]. To the best of our knowledge, no association between exercise habits and atopic eczema in childhood has been proved. In this report, we found that exercise habits could have negative effects on atopic eczema, which was more marked among boys (Table 2).

In our results, the prevalence differences were statistically unchanged after controlling for potential confounders (Table 3). Although no investigated individual-level risk factors were found to be attributable to the increasing prevalence rates of atopic eczema, we believed that changes in genetic susceptibility to atopy are unlikely to have occurred during such a short period between 1995 and 2001. Atopic eczema mostly starts in early childhood. Changes of risk factors at the current time-point might be rather important for changes in exacerbations/persistence than for changes in development of atopic eczema. A more probable explanation for the increasing prevalence is that the trend is due to a change in exposure to undefined environmental or social determinants of atopic eczema, or to other factors that promote atopic eczema in susceptible adolescents. Increased awareness of atopic eczema among the population and health care personnel could also explain the increasing prevalence over time.

The comparison from our two surveys showed a 1.61fold increase in the 12-month prevalence of atopic eczema, which suggested a 1.09-fold increase per year on average. Reviewing studies concerning the secular trends of atopic eczema in adolescents, similar rates of increase in prevalence have been reported all around the world [4, 6 , 8, 37]. However, relatively lower rates of increase were also reported from Italy and Singapore during recent years $[5,7]$.

Some previous studies agreed that outdoor air pollution was not a major risk factor for the development of atopic eczema [38, 39]. In accordance with these results, we found that none of the outdoor air pollutants were associated with the prevalence change. However, temporal change in relative humidity seems to affect the prevalence increase of atopic eczema in our study (Table 4). From a prospective study in United Kingdom, outdoor relative humidity was found to influence the occurrence of atopic eczema symptoms significantly [40]. In Germany, Vocks et al. [41] observed patients with atopic eczema and found that more intense itching symptoms increased on foggy days with a maximal relative humidity. Outdoor relative humidity is high in Taiwan (monthly average; 66.3-82.6\% between 1995 and 2000). Trans-epidermal water loss, which cools the skin through evaporation, would therefore be lower and itching symptoms would occur or exacerbate [42]. In our analysis, temporal change in relative humidity was significantly associated with prevalence increase among boys. Relative humidity was estimated to increase only $0.09 \%$, which indicated only a $0.03 \%$ prevalence increase in atopic eczema among boys and $0.01 \%$ among girls. The reasons for such a small contribution and why girls are less affected by the environmental factors that we investigated warrant additional investigation.

We also found a tendency of positive associations between temperature increase and the prevalence change of atopic eczema in both sexes (Table 4). A potential role of increased temperature in symptoms of atopic eczema has also been suggested by other studies [40, 43]. Local increases in temperature may increase outdoor pollen quantity and induce longer pollen seasons, which would provoke the development of atopic disorders [44]. There is also evidence of significantly stronger allergenicity in pollen from trees grown at an increased temperature [45]. However, Weiland et al. [46] used world-wide data from ISAAC centres and found that the prevalence of eczema symptoms was negatively associated with outdoor temperature. The inconsistent finding may be due to differences in geography, race, genetic background, and environmental exposures. Some environmental factors, such as pollens, endotoxins, or other humidity-sensitive allergens, may be affected by outdoor meteorological factors, and changes in certain factors would contribute to the increasing prevalence of atopic eczema.

Time-series approaches to analyse the association between short-term variations in ecological data and disease incidence would provide a relatively good control for confounding by individual factors. These studies are not suitable for the investigation of chronic outcomes [47], such as atopic eczema. Ecologic exposure assessment had many advantages in our study. Estimates of changes based on 22 different areas covering diverse parts of Taiwan were unlikely to be attributable to local changes in the composition of the population. The density of middle schools in Taiwan was very high and almost all the surveyed students attended schools within $1 \mathrm{~km}$ of their homes. Monitoring stations thus provided good indicators for both school and home exposure.

We do not think we have missed any important confounder in our analysis. Migrating from one community to another could lead to misclassification of ecological exposure. However, errors in exposure assessment were likely to be random, which would reduce the magnitude of association, but would not introduce a positive bias in the associations. Ecologic confounders like urbanization and socialization actually could exist and there might be 
incomplete adjustment and residual confounding. However, more complete personal risk factors were very difficult to obtain in such large-scale surveys. The exposure information obtained from monitoring stations was limited in 1995 and later years. Using air pollution and meteorology data from 1995 and estimating their changes between two surveys in exposure assessment were also rational in considering the latency period of our definition in atopic eczema.

In conclusion, this report has suggested a substantial increase in the 12-month prevalence of atopic eczema in Taiwanese adolescents, more marked among girls, and has established that several factors implicated previously were not major contributors to the observed increase. Future studies, including objective measurements, are required to investigate the contribution of changes over time in other potential aetiological factors, including levels of indoor temperature, humidity, pollutant exposure, allergen exposure, and other personal risks such as diet, stress, breast/ bottle feeding, and prenatal exposure like maternal cigarette smoking during pregnancy. In addition, the role of microbial infections in relation to atopic eczema needs to be further explored in prospective studies, because most of the recent studies have been mainly focused on asthma.

\section{Acknowledgements}

We thank all the staff of the Taiwan ISAAC Study Group for their collaboration in the participating centres. This study was partially supported by Grant \#NSC87-2621-P006-013 from the National Science Council and grant \#DOH90-TD-1138 from the Department of Health, and partly funded by Environmental Protection Administration in Taiwan.

The Taiwan ISAAC Study Group includes the following investigators: Chien-Jen Chen, Yueliang Guo, Jia-Ming Lin, and Ruey-Shiung Lin (all of the National Taiwan University, Taipei); Li-Mei Chen (Fu-Jen Catholic University, Taipei); Pesus Chou and Song-Lih Huang (both of the National Yang-Ming University, Taipei); Guang-Ming Shiao (Taipei Veterans General Hospital, Taipei); KueHsiung Hsieh (Chang Gung University, Taoyuan); BingFang Hwang, Hsien-Wen Kuo, Jim-Shoung Lai, and FungChang Sung (all of the China Medical University, Taichung); Yung-Ling Lee and Huey-Jen Su (both of the National Cheng Kung University, Tainan); Ying-Chin Ko and Ying-Chu Lin (both of the Kaohsiung Medical University, Kaohsiung); and Cheng-Kuang Shaw (Tzu-Chi University, Hualien).

\section{References}

1 The International Study of Asthma and Allergies in Childhood Steering Committee. Worldwide variation in prevalence of symptoms of asthma, allergic rhinoconjuntivitis, and atopic eczema: ISAAC. Lancet 1998; 351:1225-32.

2 Williams HC. On the definition and epidemiology of atopic dermatitis. Dermatol Clin 1995; 13:649-57.

3 Asher MI, Montefort S, Bjorksten B et al. Worldwide time trends in the prevalence of symptoms of asthma, allergic rhinoconjunctivitis, and eczema in childhood: ISAAC phases one and three repeat multicountry cross-sectional surveys. Lancet 2006; 368:733-43.

4 Grize L, Gassner M, Wuthrich B et al. Trends in prevalence of asthma, allergic rhinitis and atopic dermatitis in 5-7-year old Swiss children from 1992 to 2001. Allergy 2006; 61:556-62.

5 Galassi C, De Sario M, Biggeri A et al. Changes in prevalence of asthma and allergies among children and adolescents in Italy: 1994-2002. Pediatrics 2006; 117:34-42.

6 Bouayad Z, Aichane A, Afif A et al. Prevalence and trend of selfreported asthma and other allergic disease symptoms in Morocco: ISAAC phase I and III. Int J Tuberc Lung Dis 2006; 10:371-7.

7 Wang XS, Tan TN, Shek LP et al. The prevalence of asthma and allergies in Singapore; data from two ISAAC surveys seven years apart. Arch Dis Child 2004; 89:423-6.

8 Selnes A, Bolle R, Holt J, Lund E. Cumulative incidence of asthma and allergy in north-Norwegian schoolchildren in 1985 and 1995. Pediatr Allergy Immunol 2002; 13:58-63.

9 Selnes A, Nystad W, Bolle R, Lund E. Diverging prevalence trends of atopic disorders in Norwegian children. Results from three cross-sectional studies. Allergy 2005; 60:894-9.

10 Lee SL, Wong W, Lau YL. Increasing prevalence of allergic rhinitis but not asthma among children in Hong Kong from 1995 to 2001 (Phase 3 International Study of Asthma and Allergies in Childhood). Pediatr Allergy Immunol 2004; 15:72-8.

11 Maziak W, Behrens T, Brasky TM et al. Are asthma and allergies in children and adolescents increasing? Results from ISAAC phase I and phase III surveys in Munster, Germany. Allergy 2003; 58:572-9.

12 Toelle BG, Belousova E, Salome CM, Peat JK, Marks GB. Prevalence of asthma and allergy in schoolchildren in Belmont, Australia: three cross-sectional surveys over 20 years. BMJ 2004; 328:386-7.

13 Anderson HR, Ruggles R, Strachan DP et al. Trends in prevalence of symptoms of asthma, hay fever, and eczema in 12-14 year olds in the British Isles, 1995-2002: questionnaire survey. BMJ 2004; 328:1052-3.

14 Kluen H, Wienker T, Bieber T. Atopic eczema/dermatitis syndrome - a genetically complex disease. New advances in discovering the genetic contribution. Allergy 2003; 58:5-12.

15 Annesi-Maesano I, Oryszczyn MP, Raherison C et al. Increased prevalence of asthma and allied diseases among active adolescent tobacco smokers after controlling for passive smoking exposure. A cause for concern? Clin Exp Allergy 2004; 34:1017-23.

16 Mitchell EA, Stewart AW, ISAAC Phase One Study Group. International Study of Asthma and Allergy in Childhood. The ecological relationship of tobacco smoking to the prevalence of symptoms of asthma and other atopic diseases in children: the International Study of Asthma and Allergies in Childhood (ISAAC). Eur J Epidemiol 2001; 17:667-73. 
17 Harris JM, Cullinan P, Williams HC et al. Environmental association with eczema in early life. $\mathrm{Br} J$ Dermatol 2001; 144: 795-802.

18 McNally NJ, Williams HC, Phillips DR. Atopic eczema and the home environment. Br J Dermatol 2001; 145:730-6.

19 McNally NJ, Williams HC, Phillips DR, Strachan DP. Is there a geographical variation in eczema prevalence in the U.K.? Evidence from the 1958 British birth cohort study. $\mathrm{Br}$ J Dermatol 2000; 142:712-20.

20 Yan DC, Ou LS, Tsai TL, Wu WF, Huang JL. Prevalence and severity of symptoms of asthma, rhinitis, and eczema in 13- to 14-year-old children in Taipei, Taiwan. Ann Allergy Asthma Immunol 2005; 95:579-85.

21 Lee YL, Shaw CK, Su HJ et al. Climate, traffic-related air pollutants, and allergic rhinitis prevalence in middle-school children in Taiwan. Eur Respir J 2003; 21:964-70.

22 Lee YL, Lin YC, Hwang BF, Guo YL. Changing prevalence of asthma in Taiwanese adolescents: two surveys 6 years apart. Pediatr Allergy Immunol 2005; 16:157-64.

23 41st World Medical Assembly. Declaration of Helsinki: recommendations guiding physicians in biomedical research involving human subjects. Bull Pan Am Health Org 1990; 24:606-9.

24 Dockery DW, Cunningham J, Damokosh AI et al. Health effects of acid aerosols on North American children: respiratory symptoms. Environ Health Perspect 1996; 104:500-5.

25 Williams HC, Burney PGJ, Pembroke AC, Hay RJ. Validation of the U.K. diagnostic criteria for atopic dermatitis in a population setting. U.K. Diagnostic Criteria for Atopic Dermatitis Working Party. Br J Dermatol 1996; 135:12-7.

26 Kramer U, Schafer T, Behrendt H, Ring J. The influence of cultural and educational factors on the validity of symptom and diagnosis questions for atopic eczema. Br J Dermatol 1998; 139:1040-6.

27 Haileamlak A, Lewis SA, Britton J et al. Validation of the International Study of Asthma and Allergies in Children (ISAAC) and U.K. criteria for atopic eczema in Ethiopian children. $\mathrm{Br} J$ Dermatol 2005; 152:735-41.

28 Schafer T, Ring J. Epidemiology of allergic diseases. Allergy 1997; 52 (Suppl. 38):14-22.

29 Hopkin J. Genetics of atopy. Pediatr Allergy Immunol 1995; 6:139-44.

30 Stender M, Weiland SK, Duhme H, Keil U. Epidemiology of asthma and allergic disease. In: Environmental Health Criteria 212, principles and methods for assessing allergic hypersensitization associated with exposure to chemicals. Geneva: World Health Organization, 1999; 224-71.

31 Marks R, Kilkenny M, Plunkett A, Merlin K. The prevalence of common skin conditions in Australian school students: 2. Atopic dermatitis. Br J Dermatol 1999; 140:468-73.

32 Tay YK, Kong KH, Khoo L, Goh CL, Giam YC. The prevalence and descriptive epidemiology of atopic dermatitis in Singapore school children. Br J Dermatol 2002; 146:101-6.
33 Heinrich J, Popescu MA, Wjst M, Goldstein IF, Wichmann HE. Atopy in children and parental social class. Am J Public Health 1998; 88:1319-24.

34 Zutavern A, Hirschw T, Leupoldz W, Weiland S, Keil U, von Mutius E. Atopic dermatitis, extrinsic atopic dermatitis and the hygiene hypothesis: results from a cross-sectional study. Clin Exp Allergy 2005; 35:1301-8.

35 Arshad SH, Hide DW. Effect of environmental factors on the development of allergic disorders in infancy. J Allergy Clin Immunol 1992; 90:235-41.

36 Hjern A, Hedberg A, Haglund B, Rosen M. Does tobacco smoke prevent atopic disorders? A study of two generations of Swedish residents. Clin Exp Allergy 2001; 31:908-14.

37 Butland BK, Strachan DP, Lewis S, Bynner J, Butler N, Britton J. Investigation into the increase in hay fever and eczema at age 16 observed between the 1958 and 1970 British birth cohorts. BMJ 1997; 315:717-21.

38 Dotterud LK, Odland JO, Falk ES. Atopic disease among schoolchildren in Nikel, Russia, an Arctic area with heavy air pollution. Acta Derm Venereol 2001; 81:198-201.

39 Dotterud LK, Odland JO, Falk ES. Atopic diseases among adults in the two geographically related arctic areas Nikel, Russia and SorVaranger, Norway: possible effects of indoor and outdoor air pollution. J Eur Acad Dermatol Venereol 2000; 14:107-11.

40 Langan SM, Bourke JF, Silcocks P, Williams HC. An exploratory prospective observational study of environmental factors exacerbating atopic eczema in children. Br J Dermatol 2006; 154:979-80.

41 Vocks E, Busch R, Frohlich C, Borelli S, Mayer H, Ring J. Influence of weather and climate on subjective symptom intensity in atopic eczema. Int J Biometeorol 2001; 45:27-33.

42 Pinnagoda J, Tupker RA, Agner T, Serup J. Guidelines for transepidermal water loss (TEWL) measurement. A report from the Standardization Group of the European Society of Contact Dermatitis. Contact Dermatitis 1990; 22:164-78.

43 Williams JR, Burr ML, Williams HC. Factors influencing atopic dermatitis - a questionnaire survey of schoolchildren's perceptions. Br J Dermatol 2004; 150:1154-61.

44 Beggs PJ, Bambrick HJ. Is the global rise of asthma an early impact of anthropogenic climate change? Environ Health Perspect 2005; 113:915-9.

45 Ahlholm JU, Helander ML, Savolainen J. Genetic and environmental factors affecting the allergenicity of birch (Betula pubescens ssp. czerepanovii [Orl.] Hamet-ahti) pollen. Clin Exp Allergy 1998; 28:1384-8.

46 Weiland SK, Husing A, Strachan DP, Rzehak P, Pearce N., ISAAC Phase One Study Group. Climate and the prevalence of symptoms of asthma, allergic rhinitis, and atopic eczema in children. Occup Environ Med 2004; 61:609-15.

47 McMichael AJ, Anderson HR, Brunekreef B, Cohen AJ. Inappropriate use of daily mortality analyses to estimate longer-term mortality effects of air pollution. Int J Epidemiol 1998; 27:450-3. 